\title{
Recent results of treatment of infantile hypertrophic pyloric stenosis
}

\author{
B ZEIDAN, ${ }^{*}$ J WYATT, $*$ A MACKERSIE, $\dagger$ AND R J BRERETON*
}

Departments of *Surgery and †Anaesthesia, Hospital for Sick Children, Great Ormond Street, and Queen Elizabeth Hospital, London

SUMMARY During the five year period December 1980 to November 1985, 106 infants with hypertrophic pyloric stenosis were treated. There were no operative deaths, but two late deaths occurred from associated abnormalities. The combination of preoperative rehydration, skilled anaesthesia, and the use of the Fredet-Ramstedt operation (pyloromyotomy) have virtually ${ }_{0}^{\circ}$ eliminated mortality from uncomplicated infantile hypertrophic pyloric stenosis. The most 0 common complications were gastro-oesophageal reflux in $11(11 \%)$, perforation of the duodenal $\rightarrow$ fornix in nine $(8 \%)$, and wound infection in five $(5 \%)$; no wound dehisced.

Several authors ${ }^{1-3}$ have suggested that infants treated for hypertrophic pyloric stenosis in Britain still have unacceptably high complication rates compared with those treated in the United States, where experts have criticised British results. ${ }^{4}$ Recent results at this hospital have been analysed to ascertain where improvements could be made.

\section{Patients and methods}

Between December 1980 and November 1985, 106 consecutive infants with pyloric stenosis were treated by one surgical team at this hospital; three were lost to follow up. Other serious associated anomalies necessitated the admission of four boys and eight girls (table 1) who will be discussed separately, but the remaining 72 boys and 19 girls (tables 2 and 3) were treated primarily for hypertrophic pyloric stenosis. In 85 of the 91 infants the diagnosis was made clinically, ${ }^{4}$ but 12 infants underwent barium meal examination even though a pyloric tumour could be felt in six of them.

In all infants oral feeding was discontinued, a nasogastric tube was passed, and the stomach emptied. Milk curds were removed by lavage with warm saline. An intravenous infusion of $0.18 \%$ saline in $4 \%$ dextrose was given, and hypokalaemic alkalosis was corrected with $0.9 \%$ saline containing $10 \mathrm{mmol}$ of potassium chloride in each $500 \mathrm{ml}$ of saline. Infants judged to be dehydrated by more than $15 \%$ were given $30 \mathrm{ml} / \mathrm{kg}$ of plasma. Operation was performed on the next available list. To avoid unnecessary delay operations were occasionally
Table 1 Associated abnormalities in 103 infants with pyloric stenosis

\begin{tabular}{|c|c|}
\hline Abnormality & $\begin{array}{l}\text { No of } \\
\text { infants }\end{array}$ \\
\hline $\begin{array}{l}\text { Major abnormalities: } \\
\text { Oesophageal atresia } \\
\text { Intestinal malrotation } \\
\text { Oesophageal atresia and intestinal malrotation } \\
\text { Necrotising enterocolitis }\end{array}$ & $\begin{array}{l}5^{*} \\
4 \\
2 \\
1^{*}\end{array}$ \\
\hline $\begin{array}{l}\text { Minor abnormalities: } \\
\text { Meckel's diverticulum } \\
\text { Inguinal hernia } \\
\text { Undescended testis } \\
\text { Vesicoureteric reflux and urinary infection } \\
\text { Cardiovascular }\end{array}$ & $\begin{array}{l}1 \\
6 \\
2 \\
1 \\
3\end{array}$ \\
\hline \multicolumn{2}{|l|}{ *Include two late deaths. } \\
\hline & $\begin{array}{l}\text { No of } \\
\text { infants }\end{array}$ \\
\hline $\begin{array}{l}\text { Boys } \\
\text { Girls }\end{array}$ & $\begin{array}{l}72 \\
19\end{array}$ \\
\hline Firstborn boys & 7 \\
\hline Premature babies & 6 \\
\hline One of twins & 2 \\
\hline $\begin{array}{l}\text { Family history of pyloric stenosis:* } \\
\text { Boys } \\
\text { Girls }\end{array}$ & $\begin{array}{l}5 \\
5 .\end{array}$ \\
\hline
\end{tabular}

*Includes three siblings from one family, and two sisters fromo another. 
Table 3 Factors associated with diagnosis of 91 infants treated primarily for hypertrophic pyloric stenosis

\begin{tabular}{lc}
\hline & No \\
\hline Mean (range) age at onset of symptoms (days) & $27(0-75)$ \\
Mean (range) birth weight (g) & $3079(1200-4390)$ \\
Weight: & \\
Gained & 76 \\
Maintained birth weight & 3 \\
Lost & 12 \\
Palpable pyloric tumour & 85 \\
Preoperative barium meal examination & 12 \\
\hline
\end{tabular}

performed during weekends, but they were never done as emergencies.

One patient underwent operation under local anaesthesia for religious reasons, but the remainder had general anaesthesia with endotracheal intubation. Infants were extubated when fully awake. ${ }^{6}$ Opiate analgesics were not prescribed because infants of less than 46 weeks' gestational age (full term plus six weeks) have an appreciable risk of postoperative apnoea. ${ }^{7}$

A modification of Robertson's gridiron incision ${ }^{8}$ was used in all but the infant having the operation under local anaesthesia. In earlier cases the hypertrophied muscle was split using either mosquito artery forceps or a Denis Browne pyloric spreader; more recently the surgeon simply turned the scalpel in his hand and used the rounded end. The handle of the Swann-Morton scalpel makes an excellent split in the pylorus without risk of damage to the duodenal mucosa. If the parents consented the appendix was removed by the inversion technique (which avoids bacterial contamination of the operative field and does not predispose to intussusception provided the appendix is devascularised). ${ }^{9}$ Two infants underwent inguinal herniotomy during the same operation. The muscles of the abdominal wall were closed with 000 polyglycolic acid, and the same suture was used as a subcuticular stitch. Dressings were not used.

To prevent hypoglycaemia, the intravenous infusion of $0 \cdot 18 \%$ saline with $4 \%$ dextrose at $2-3 \mathrm{ml} / \mathrm{kg} /$ hour was continued until the infant was feeding normally. ${ }^{6}$ The timing of the reintroduction of feeds was left to the discretion of the nurse in charge of the ward, and no specific regimen was used. Nearly all the operations were performed during afternoon operating sessions so feeding usually began late the next morning. In nine infants the duodenal mucosa was breached so the nasogastric tube was retained for 24 hours and feeds omitted during that time.

\section{Results}

Pyloric obstruction was relieved in all infants, and none required reoperation. There were no operative deaths and no deaths among those without serious associated abnormalities. In nine infants the duodenal fornix was perforated by surgeons in training using artery forceps or muscle spreaders. In each case the duodenum was oversewn with 0000 chromic catgut and patched with omentum, and all recovered uneventfully. This complication has not occurred since artery forceps and spreaders were abandoned in favour of the scalpel handle. One infant had a severe reactionary haemorrhage requiring blood transfusion and developed an abscess (pus from which grew Staphylococcus aureus) at the drip site. There were four wound infections, three of which required treatment with antibiotics; $S$ aureus was isolated from two of these. There were no wound dehiscences, and no incisional hernias had developed by follow up at three months. Prolonged follow up was thought unnecessary and to date none of the infants has returned to this hospital for repair of an incisional hernia.

The first postoperative feed was at a mean of 21 hours (range 4-84) after operation, and patients were sent home a mean of 76 hours (range 22-168) after operation. Those with iatrogenic duodenal perforations were in hospital for about 18 hours longer than the others (mean 94 hours, range 70-122) but the main reasons for prolonged hospital stay were associated gastro-oesophageal reflux, and wound infection. Some babies were not collected promptly by their parents.

Postoperative vomiting occurred in half the infants, and usually lasted two or three days. Vomiting persisted in nine of the 91 infants without other serious abnormalities, and all of these had barium meal examinations; six were shown to have severe gastro-oesophageal reflux. Sliding hiatal hernias were present in three of these, but only one had oesophagitis at endoscopy. All recovered spontaneously after several weeks.

Seven infants presented with oesophageal atresia, two of whom also had intestinal malrotation (table 1). One girl had Royer's syndrome ${ }^{10}$ with associated intestinal malrotation, and she developed a wound infection with $S$ aureus. Two of the infants with intestinal malrotation failed to stop vomiting despite the Ladd's and Ramstedt's procedures, and one underwent Nissen fundoplication at the age of 18 months. These infants obviously stayed in hospital much longer than those with isolated pyloric stenosis.

Associated anomalies caused two late deaths. A girl had birth asphyxia, colonic perforation from necrotising enterocolitis, and developed pyloric 
Table 4 Percentages of postoperative complications in reported series from the United States and Great Britain

\begin{tabular}{|c|c|c|c|c|c|c|}
\hline Authors & Mortality & $\begin{array}{l}\text { Mucosal } \\
\text { perforation }\end{array}$ & $\begin{array}{l}\text { Wound } \\
\text { infection }\end{array}$ & $\begin{array}{l}\text { Wound } \\
\text { dehiscence }\end{array}$ & $\begin{array}{l}\text { Incisional } \\
\text { hernia }\end{array}$ & Bleeding \\
\hline \multicolumn{7}{|l|}{ United States: } \\
\hline Pollock et al, $1957^{4}$ & $1 \cdot 7$ & $0 \cdot 5$ & $3 \cdot 0$ & $2 \cdot 0$ & 0 & $1 \cdot 0$ \\
\hline Benson and Lloyd, $1964^{14}$ & 0.6 & $2 \cdot 1$ & 4.9 & $0 \cdot 09$ & 0.09 & 0 \\
\hline Bell, $1968^{13}$ & $0 \cdot 32$ & $3 \cdot 0$ & 0.3 & $0 \cdot 3$ & 0 & 0 \\
\hline Schärli et al, $1969^{16}$ & $2 \cdot 9$ & $1 \cdot 2$ & $1 \cdot 6$ & 0.4 & 0 & 0.4 \\
\hline Gibbs et al, $1975^{15}$ & 0 & $0 \cdot 8$ & 0.8 & 0 & 0 & 0 \\
\hline \multicolumn{7}{|l|}{ Great Britain: } \\
\hline Prosser, $1965^{17}$ & 0.3 & 0.7 & 0.7 & 0 & 0 & 0 \\
\hline Dougall, $1969^{19}$ & 0.5 & $3 \cdot 5$ & $14 \cdot 0$ & $1 \cdot 5$ & $3 \cdot 0$ & 0 \\
\hline Bristol and Bolton, $1981^{1}$ & 0 & $11 \cdot 5$ & $9 \cdot 0$ & $3 \cdot 8$ & 0 & 0 \\
\hline Carle and Davidson, $1985^{3}$ & 0 & $7 \cdot 2$ & $9 \cdot 5$ & 0.4 & 0.4 & 0.8 \\
\hline Present series & 0 & $8 \cdot 5$ & $4 \cdot 7$ & 0 & 0 & 0.9 \\
\hline
\end{tabular}

stenosis during recovery. Despite pyloromyotomy she never fed normally and became profoundly retarded. She died shortly after returning to the referring hospital. Another girl was originally treated elsewhere for oesophageal atresia, never fed orally, and was referred to our care at the age of 6 months. Pyloric stenosis was diagnosed and treated, but numerous operations were required for complications of the oesophageal repair. She died suddenly and inexplicably after colonic replacement of the oesphagus at the age of 3 years.

\section{Discussion}

The development of the treatment of pyloric stenosis has been well recorded. ${ }^{11-13}$ For many years excellent results have been reported for the FredetRamstedt operation from the United States, ${ }^{411-16}$ but-outside selected centres ${ }^{17-19}$-inferior results have been recorded in Britain. ${ }^{12}$ As late as 1945, mortality as high as $25 \%$ was being reported in Britain. ${ }^{18}$ Death from pyloric stenosis alone should not occur, ${ }^{14}$ but occasional deaths are attributed either to anaesthesia or operation. ${ }^{20}$

Projectile non-bilious vomiting is said to be the hallmark of pyloric stenosis, ${ }^{413}$ but in our experience the nature of the vomiting is rarely helpful in diagnosis; projectile vomiting has also been described in infants with gastro-oesophageal reflux, and nonprojectile vomiting in those with pyloric stenosis. ${ }^{1}$ In the absence of a palpable tumour diagnosis may be difficult, and paediatricians usually request barium meal examination. In the past some authorities ${ }^{13}$ have recommended radiological examination in all cases; now that the dangers of neonatal irradiation are appreciated, however, most experts condone radiological diagnosis only in difficult case ${ }^{11}$ though barium studies are often equivocal when there is clinical doubt. ${ }^{1821}$ Shopfner et $a l^{22}$ were erroneously credited with the pronouncement 'no palpable tumour-no surgery', a policy that causes unneces-

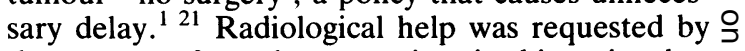
the surgeons for only one patient in this series, but $\vec{C}$ contrast meals had been performed in 11 cases by $\mathcal{D}_{\mathbb{D}}$ referring paediatricians. ${ }^{16}$ In other series, between 3 and $25 \%$ of infants were submitted to radiological examination. ${ }^{1} 141619$ Ultrasound examination is $\mathbb{\Phi}_{\mathbb{C}}$ popular now, ${ }^{23}$ but in our experience is unreliable when there are serious doubts about the clinical $\phi$ signs.

Preparation for operation need not be $\varnothing$ hurried, ${ }^{12} 1317$ and most clinicians use intravenous fluid replacement, ${ }^{6}$ though some prefer oral rehydration. ${ }^{13}$ Of our patients, $95 \%$ were mildly dehydrated, $3 \%$ moderately so, and only one infant $\frac{\varnothing}{\varnothing}$ severely so. ${ }^{324}$ Operation was always done within $\stackrel{2}{\vec{F}}$ 48 hours of admission, and usually within 24 hours. $^{11214181924}$ Respiratory depression or $\frac{3}{\sqrt{3}}$ arrest are serious postoperative complications that may be caused by inadequate rehydration before operation. ${ }^{1}$ Fluid and electrolyte imbalance also predispose to postoperative shock and convul- $\frac{}{2}$ sions. $^{1624}$ It is essential to guard against hypo- 3 . thermia during the operation, and the effects of muscle relaxants and anaesthesia must be reversed before the endotracheal tube is removed. ${ }^{6}$

A vertical incision should be avoided because the scar becomes increasingly obvious as the child grows, ${ }^{413}$ especially if a paramedian incision has been closed with tension sutures. The skin of the o hypochondrium in the infant migrates superiorly N and comes to lie over the lower chest in the adult, so N an unusually high transverse subcostal incision in $\mathrm{a}_{\sigma}^{\omega}$ neonate may give rise to an ugly thoracic scar in adolescence. Wound dehiscence after pyloromyotomy used to be fairly common (table 4), and $\stackrel{\mathbb{\Phi}}{\hookrightarrow}$ remains so in those undergoing operation under local anaesthesia. ${ }^{12}$ Tension sutures ${ }^{3}$ are unnecessary with Robertson's incision, which rarely 
dehisces. ${ }^{525}$ Skilled general anaesthesia provides ideal operating conditions permitting the routine use of Robertson's incision by junior surgeons, but it is extremely difficult to operate through a small gridiron incision without adequate muscle relaxation. ${ }^{1}$ During the period of our review two infants (originally operated upon elsewhere) had their wounds resutured.

Some experts in Britain are extremely critical of a surgeon who perforates the duodenal fornix, but this has not been an important complication in this series. ${ }^{16}$ It is more common for a timid surgeon to perform an incomplete pyloromyotomy necessitating reoperation than it is for a bold one to cause serious postoperative complications by making a small hole in the duodenum - as long as this is recognised immediately and treated appropriately. ${ }^{413}$ During the period of our review two infants, not included in our results, were referred for repeat pyloromyotomy after unsuccessful operations elsewhere.

Postoperative care in hospital need not be prolonged, ${ }^{14}{ }^{15}$ and Prosser aimed at discharging his patients the next day, although the average postoperative stay was 52 hours. Prolonged hospital stay is caused by complications that occur in $10-20 \%$ of infants. $^{216}$ Serious haemorrhage after pyloromyotomy tends to be played down and many authors suggest that no steps need be taken to control the bleeding, though such laxity has been criticised ${ }^{15}$ and deaths from haemorrhage have been recorded. ${ }^{4}$ Appreciable postoperative bleeding occurs in up to $7.5 \%$ of patients ${ }^{16} 19$ and after our salutary experience with one serious haemorrhage we have taken greater steps to secure haemostasis.

In the past, about three quarters of the deaths were caused by infection, including pneumonia, peritonitis, and septicaemia. Gastroenteritis also used to be a major cause of death or morbidity, ${ }_{1622}$ but none occurred in our patients. Wound infection is a common complication (table 4), and recent reports from Britain give rates of about $10 \% .^{1-3}$ Organisms gain access to the wound from the umbilicus. ${ }^{25}{ }^{26}$ We excluded the umbilicus from the wound with an adhesive drape ${ }^{25}$ but still had an infection rate of $5 \%$. The commonest organism to be isolated is $S$ aureus $^{2}{ }^{25}$ so it has been suggested that antistaphylococcal antibiotics should be given shortly before operation. In our series the wound infection rate was unaffected by duodenal perforation or inversion appendicectomy.

Postoperative vomiting occurs in 30 to $95 \%$ of

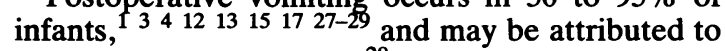
preoperative oesophagitis ${ }^{28}$ or to the use of general anaesthesia, ${ }^{1}$ though the latter has been disputed. ${ }^{2}{ }^{3}$ Vomiting is to be expected for two to three days 4 and it is known that gastric emptying is inefficient for the first 18 hours after operation, ${ }^{27}$ so early feeding should be avoided. Numerous feeding regimens have been used to overcome this problem ${ }^{414} 17$ including delayed feeding, ${ }^{28} 29$ but none has been completely successful. Like Prosser ${ }^{17}$ we adopt a pragmatic approach and attach little importance to vomiting during the first 48 hours after operation. Of more importance is the vomiting that persists for several weeks after adequate pyloromyotomy. ${ }^{28}$ Forshall $^{30}$ was one of the first surgeons to recognise the association between pyloric stenosis and incompetence of the lower oesophageal sphincter. Symptomatic gastro-oesophageal reflux occurs in 10 to $13 \%$ of patients. ${ }^{30} 31$ The postoperative barium meal examination is helpful in the diagnosis of reflux, but of little value in the assessment of the pylorus because the radiological appearances of stenosis may persist for many months. ${ }^{27} 32$

Nowadays the prognosis for infants with pyloric stenosis depends on the associated anomalies, which are present in 6 to $20 \%$ of patients. ${ }^{13141633}$ The association with oesophageal atresia is well known ${ }^{4} 143334$ but sometimes difficult to establish without radiological help, especially in those with a gastrostomy. The association with rectal agenesis ${ }^{4}$ or Hirschsprung's disease ${ }^{18}$ is less well known, as is that with cleft lip and palate ${ }^{16}$ which makes feeding difficult. Congenital heart disease is an occasional association, ${ }^{4} 1516$ and two of our patients underwent successful aortic valvotomies. Minor renal anomalies have been detected in up to $20 \%$ of patients, ${ }^{34}$ undescended testis in 3\%, hypospadias in $0.9 \%$, and inguinal hernia in up to $10 \% .{ }^{15}$ Of our 103 patients, six had already undergone inguinal herniotomy, but the explanation for this association is not apparent. ${ }^{34}$ We have observed that infants with these minor anomalies commonly vomit for several days after operation and, of the nine infants with persistent postoperative vomiting, two had had inguinal hernias repaired and one girl had vesicoureteric reflux causing urinary tract infection. Intestinal malrotation was an important association in our series, though this has been reported infrequently in the past. ${ }^{16} 1835$

Our results could have been improved by ensuring that the pylorus was split with a blunt instrument, by greater attention to haemostasis, and by more vigorous attempts to prevent wound infection, possibly by using prophylactic antistaphylococcal antibiotics. Fewer contrast radiographs should have been done, and postoperative vomiting should have been anticipated in infants with minor associated anomalies. Uncomplicated cases should have been discharged within 48 hours of operation. Infants with major associated anomalies should be treated in regional centres, and otherwise healthy infants 
being treated in district general hospitals should be treated by surgeons and anaesthetists with a special interest in paediatric surgery. ${ }^{1}$

\section{References}

1 Bristol JB, Bolton RA. The results of Ramstedt's operation in a district general hospital. Br J Surg 1981;68:590-2.

2 Gray DW, Gear MW, Stevens DW. The results of Ramstedt's operation: room for complacency? Ann R Coll Surg Engl; 1984; 66: $280-2$.

3 Carle G, Davidson AI. Infantile pyloric stenosis in the North East of Scotland. Result of Ramstedt's operation in 264 cases. $J$ R Coll Surg Edinb 1985;30:30-3.

4 Pollock WF, Norris WJ, Gordon HE. The management of hypertrophic pyloric stenosis at the Los Angeles Children's Hospital; a review of 1422 cases. Am J Surg 1957;94:335-49.

${ }^{5}$ Gross RE. Congenital hypertrophic stenosis. The surgery of infancy and childhood. Philadelphia; WB Saunders, 1953: 130-43.

6 Daly AM, Conn AW. Anaesthesia for pyloromyotomy: a review (the Hospital for Sick Children, Toronto). Can Anaesth Soc J 1969;16:314-20.

${ }^{7}$ Gregory GA, Steward DJ. Life-threatening perioperative apnoea in the ex-"premie". Anesthesiology 1983;59:495-8.

8 Robertson DE. Congenital pyloric stenosis. Ann Surg 1940;112: 687-99.

9 Bishop HC, Filston HC. An inversion-ligature technique for incidental appendicectomy. J Pediatr Surg 1973;8:889-92.

10 Royer P, Ricour C, Nihoul-Fekete C, Pellerin D. Le syndrome familial de grele court avec malrotation intestinale et stenose hypertrophique du pylore chez le nourrisson. Arch Franc Pediatr 1974;31:223-9.

11 Hayes MA, Goldenberg IS. The problems of infantile pyloric stenosis. International Abstracts of Surgery 1957;104:105-38.

12 Benson CD. Infantile pyloric stenosis: historical aspects and current surgical concepts. Progress in Pediatric Surgery 1971;1: 63-88.

${ }^{13}$ Bell MJ. Infantile pyloric stenosis: experience with 305 cases at Louisville Children's Hospital. Surgery 1968;64:983-9.

${ }^{14}$ Benson CD, Lloyd JR. Infantile pyloric stenosis: a review of 1120 cases. Am J Surg 1964;107:429-33.

15 Gibbs MK, van Heerden JA, Lynn HB. Congenital hypertrophic pyloric stenosis: surgical experience. Mayo Clin Proc 1975;50: 312-6.

${ }^{16}$ Schärli A, Sieber WK, Kiesewetter WB. Hypertrophic pyloric stenosis at the Children's Hospital of Pittsburgh from 1912 to 1967. J Pediatr Surg 1969;4:108-14.

17 Prosser R. Infantile hypertrophic pyloric stenosis. Surgery 1965;58:881-3.
18 Cook RCM, Rickham PP. Gastric outlet obstruction. In: Rickham PP, Lister J, Irving IM, eds. Neonatal Surgery. 2nd ed. London: Butterworths, 1978:335-51.

19 Dougall AJ. Infantile pyloric stenosis: a review of 200 cases. Scott Med J 1969;14:156-61.

${ }^{20}$ Lunn JN, Hunter AR, Scott DB. Anaesthesia-related surgical mortality. Anaesthesia 1983;38:1090-6.

21 Larsen GL. Limitations of roentgenographic examination in the diagnosis of infantile hypertrophic pyloric stenosis. Surgery 1966;60:768-72.

22 Shopfner CE, Kalmon EH, Coin CG. The diagnosis of hypertrophic pyloric stenosis. AJR 1964;91:796-800.

23 Tunell WP, Wilson DA. Pyloric stenosis: diagnosis by real time sonography, the pyloric muscle length method. $J$ Pediatr Surg 1984;19:795-9.

24 Benson CD, Alpern EB. Preoperative and postoperative care of congenital pyloric stenosis. Arch Surg 1957;75:877-9.

25 Fitzgerald RJ. The results of Ramstedt's operation: room for complacency. Ann $R$ Coll Surg Engl 1984;66:449.

26 Tan KC, Bianchi A. Circumumbilical incision for pyloromyotomy. Br J Surg 1986;73:399.

27 Schärli AF, Leditschke JF. Gastric motility after pyloromyotomy in infants: a reappraisal of postoperative feeding. Surgery 1968;64:1133-7.

28 Spitz L. Vomiting after pyloromyotomy for infantile hypertrophic pyloric stenosis. Arch Dis Child 1979;54:886-9.

29 Leahy A, Fitzgerald RJ. The influence of delayed feeding on postoperative vomiting in hypertrophic pyloric stenosis. $\mathrm{Br} J$ Surg 1982;69:658-9.

30 Forshall I. The cardio-oesophageal syndrome in childhood. Arch Dis Child 1955;30:46-54.

31 Pellerin D, Bertin P, Tovar JA. Reflux gastro-oesophagien et stenose hypertrophique du pylore. Ann Chir Infantile 1973;15: 7-14.

${ }^{32}$ Steinicke O, Roselgaard M. Ragiographic follow-up in hypertrophic pyloric stenosis (after medical and surgical treatment). Acta Paediatr Scand 1960;49:4-16.

33 Ahmed S. Infantile pyloric stenosis associated with major anomalies of the alimentary tract. J Pediatr Surg 1970;5:660-6.

34 Atwell JD, Levick P. Congenital hypertrophic pyloric stenosis and associated anomalies in the genitourinary tract. $J$ Pediatr Surg 1981;16:1029-34.

35 Gross RE. Malrotation of intestines and colon. The surgery of infancy and childhood. Philadelphia: WB Saunders, 1953: 192-203.

Correspondence to $\mathrm{Mr} \mathrm{RJ}$ Brereton, Department of Surgery, Hospital for Sick Children, Great Ormond Street, London WC1N 3JH.

Accepted 15 February 1988 